\title{
Novel Coronavirus-2019 (COVID-19)- A genetically mutant of Severe Acute Respiratory Syndrome $\beta$-Coronavirus
}

\author{
Khan Salman ${ }^{1 *}$, Singh Priti ${ }^{2}$, Zefenkey Zean ${ }^{3}$ and Salieva Rana \\ ${ }^{1}$ Assistant Professor, Department of Pathological Analysis, Knowledge University, \\ Erbil, Iraq \\ ${ }^{2}$ International Medical Faculty Osh State University, Osh, Kyrgyzstan \\ ${ }^{3}$ Lecturer, Department Pathological Analysis, Knowledge University, Erbil, Iraq \\ ${ }^{4}$ Lecturer, Department of Pulmonary, Osh state university, Osh, Kyrgyzstan \\ *Corresponding Author: Khan Salman, Assistant Professor of Medical Microbiology and \\ Immunology, Department of Pathological Analysis, Knowledge University, Erbil, Iraq. \\ DOI: 10.31080 /asmi.2020.03.0573
}

\section{Abstract}

Many coronaviruses (CoVs) causing a variety of pathological disease in animals and maintained their cycle in nature and causing zoonotic infections, allowing them for genetic recombination, resulting in novel viruses. Seven CoVs have been isolated from the infected humans; causing mild to severe disease in humans, newly emerged from a zoonotic source that are 229E, OC43, HKU1, NL63, Severe Acute Respiratory Syndrome-(SARS-CoV), Middle East respiratory syndrome (MERS-CoV) and Novel CoV in 2019 (nCoV19). SARS-CoVs have been isolated during 2002 - 2003 outbreak in China. MERS-CoV was responsible of an outbreak in Middle East during 2012-2015 resulted by the genetic recombination in camels and transmitted to humans. nCoV-19 is responsible for an ongoing outbreak of severe respiratory disease which was first reported from china in December 2019 and their genome is significantly different from SARS-CoV to be considered a new human-infecting $\beta-\mathrm{CoV}$ which might be using their spike protein to bind to the angiotensin-converting enzyme 2 receptor (ACE2R) expressed on alveolar epithelial type II cells using it for their replication. ACE2R is also found in many extrapulmonary tissues like kidney, heart, endothelium, and luminal surface of intestinal epithelial cells which enforced to focused for fecal-oral transmission and containment of viral spread and multi-organ dysfunction in patients ACE2R regulates both the cross-species and human-to-human transmissions and also suggesting that bats might be the original host of nCoV-19. CoVs transmitting predominantly during the winter season in temperate-climate countries. CoVs can be diagnosed by serological tests, cultured by cell culture techniques and Nucleic acid amplification tests, and gene sequencing for the confirmatory tests. Currently, there is no vaccination to prevent the patients by nCoV-19. Only prevention is the best way to avoid being exposed to this virus. Favilavir, Chloroquine and Remdesivir drugs are under trials. nCoV-19 might be neutralized by providing high dose of soluble form of ACE2 and might recover cellular ACE2 activity by negative feed back system of renin angiotensin and protect the lung injury. Protein S1 domain of Spike-subunit based vaccine produced by Cell lines method, Inhibitor of transmembrane protease serine 2 to inhibit entry and viral spread can be try to curb this virus.

Keywords: Novel Coronaviruses 2019; Coronaviruses; COVID-19; Angiotensin-Converting Enzyme 2; Severe Acute Respiratory Syndrome

\section{Introduction}

Human coronaviruses (HCoVs) were first described in the 1960s for patients with the common cold [1]. Coronaviruses are enveloped RNA viruses that are causing infection in respiratory tract and can cause enteric, hepatic, and neurologic diseases [2,3]. HCoV-HKU1, OC43, NL63 and 229E viruses are prevalent and typically cause common cold symptoms in immunocompromised individuals like older age or AIDS patients [4] and Middle East respiratory syndrome coronavirus (MERS-CoV) and severe acute respiratory syndrome coronavirus (SARS-CoV) are zoonotic in origin which have been causing infection in humans [5]. In 2002 and 2003 SARS-CoV disease emerged in Guangdong Province of China. The following year one of the doctors who had been treating pa- tients travelled to Hong Kong, where he became ill and died. Subsequently, people who had stayed in the same hotel as the doctor travelled to Singapore, Vietnam, Canada and the US, taking the infectious agent with them. The epidemic of severe acute respiratory syndrome (SARS) was under way [6-8].

No natural reservoir for the SARS-CoV has been found, but with very similar genome sequences were isolated from animals sold in markets in the region of China where the first SARS-CoV cases appeared. Antibodies to these viruses were found in many workers in the markets, but none of the workers had any history of SARS-CoV. A similar virus has also been isolated from several bat species. It is likely that coronaviruses have repeatedly crossed into humans 
from other mammalian species, but in the majority of cases the virus has lacked the ability for efficient human-to-human transmission. It would seem that the SARS coronavirus evolved from a rare virus that had this ability [9].

Coronaviruses are classified into four genera based on phylogeny: $\beta-\operatorname{CoV}$ (group 1), $\beta-\operatorname{CoV}$ (group 2), $\beta-\operatorname{CoV}$ (group 3) and $\beta-\operatorname{CoV}$ (group 4). A, B, C and D Lineages were documented in $\beta$-CoV genus. Lineage $A$ viruses of $\beta-\mathrm{CoV}$ also encode a smaller protein called hemagglutinin esterase which is similar to the $S$ protein in function [10].

\section{SARS-CoV ( $\beta$-CoV- lineage-B)}

Patients infected with SARS-CoV initially present with fever, myalgia, headache, malaise, and chills, followed by a dry cough, dyspnea and respiratory distress generally 5 - 7 days later, which may cause patient death [11]. Other notable features in some cases include infection of the gastrointestinal tract, liver, kidney and brain. Innate immune defenses in the lung include epithelial barrier, mucociliary clearance, antimicrobial peptides, complement components and surfactants; reduces cilia, thus impacting mucus removal; Tissue destruction and respiratory infections in the lungs of patients with SARS-CoV and critical in mounting adequate host immune responses and constitutively activates alveolar macrophages, monocytes, mast cells, natural killer, dendritic cells, neutrophils and CD8+ T cells are the immune cells considered the prime effector cells which involve in the immunological changes in SARS-CoV infection of the lung [12]. Phagocytes control infection and accelerate the resolution of infection associated inflammation. During an inflammatory response, alveolar macrophages phagocytose infiltrated neutrophils to control infection [13]. Lymphopenia, hemophagocytosis in the lung, in addition to white-pulp atrophy of the spleen observed in SARS patients, are similar to fatal H5N1 influenza virus infections [11]. Diarrhea is observed in approximately $30-40 \%$ of SARS infections.

\section{A novel coronavirus (nCoV-19)}

China in December 2019, the new coronavirus has rapidly spread in Wuhan, China and spread to the entire China and some neighboring countries named novel Coronavirus-2019 which is the seventh member of the family of Coronaviridae that infect humans. Which belongs to subgenus sarbecovirus, subfamilyOrthocoronavirinae and differs from both MERS-CoV and SARSCoV. More than $85 \%$ of the genome of $\mathrm{nCoV}-19$ was matched with a bat SARS-like CoV (bat-SL-CoVZC45, MG772933.1) from genus $\beta$-CoV- lineage-B. Although nCoV-19 was similar to some $\beta$-CoV detected in bats in china, it was distinct from SARS-CoV and MERS$\mathrm{CoV}$ [14]. The three nCoV-19 from Wuhan, together with two batderived SARS-like strains, ZC45 and ZXC21, form a distinct clade. SARS-CoV strains from humans and genetically similar SARS-like
$\mathrm{CoV}$ from bats collected from southwestern China formed another clade within the subgenus sarbecovirus. Since the identification of sequence in conserved replicase domains (ORF $1 \mathrm{ab}$ ) is less than $90 \%$ between $n \mathrm{CoV}-19$ and other members of $\beta-\mathrm{CoV}$. nCoV-19 was infected viral pneumonia in Wuhan patients and named "novel coronavirus-infected pneumonia [14].

\section{Mutation and genetic recombination in coronaviruses}

CoVs have the largest RNA genomes described to date with some reaching almost 30,000 nt. The single, linear, positive sense, ssRNA molecule has a $5^{\prime}$ cap and a $3^{\prime}$ poly A tail. All CoVs share similarities in the organization and expression of their genome, in which 16 nonstructural proteins (nsp1 through nsp16), encoded by open reading frame (ORF) $1 \mathrm{a} / \mathrm{b}$ at the $5^{\prime}$ end and on the other hand the structural proteins spike (S), envelope (E), membrane (M), and nucleocapsid (N), are encoded by other ORFs at the 3' end [15].

The virus using their spike protein receptor-binding to its host receptor angiotensin-converting enzyme 2 which regulate both the cross-species and human-to-human transmissions after getting entry into the host cell, virus uncoating is translation of the virus genome RNA to produce the virus RNA dependent RNA polymerase enzyme in the host cytoplasm. With the help of this enzyme and by using the plus-strand as template, Virus make double-stranded RNA then transcribes positive sense RNA from a negative sense RNA template in an RI replication complex [15].

The first event of translation directs the synthesis of two proteins from the genome RNA. The smallest, the 1a protein, is translated from the first $\mathrm{ORF}$ which represents only a small proportion of the molecule. A second, larger, protein is also produced, though in smaller amounts, and this is thought to contain the enzymatic component of the polymerase. The way in which the two proteins function together is not known. Nucleotide sequence analysis identified an ORF near the $5^{\prime}$ end of the genome RNA capable of synthesizing the 1a protein but no ORF long enough to encode the larger protein, called the $1 \mathrm{~b}$ ORF, lacking an AUG initiation codon and overlapping with the 3 'end of the $1 \mathrm{a}$ ORF is present. The $1 \mathrm{~b}$ ORF is in the -1 reading frame with respect to the 1a ORF. The large protein is generated by a proportion of ribosomes which initiate translation in the 1a ORF switching reading frames in the region of the overlap of the 1a and $1 \mathrm{~b}$ ORFs while continuing uninterrupted protein synthesis to generate a fusion $1 \mathrm{a}-1 \mathrm{~b}$ protein [15].

A similar event occurs in the synthesis of certain Retroviruses gag-pol fusion proteins. The amount of the fusion protein produced is determined by the frequency of the frameshifting event. The frameshifting event in $\mathrm{CoV}$ is determined by the presence of two structural features in the genomic RNA. The first is a "slippery" sequence in the region of overlap between the ORFs at which the 
frameshift occurs and the second is a three-dimensional structure called a pseudoknot in which the RNA is folded into a tight conformation. These two features combine to effect the frameshift [15]. The mutation rates are moderate to high in $\mathrm{CoV}$ as compared to other ssRNA-viruses, and the average substitution rate was $\sim 10^{-4}$ substitutions per year per site [16]. For SARS-CoV, the mutation rate in the whole genome was estimated to be $0.80-2.38 \times 1-3$ nucleotide substitutions/site/year, and the non-synonymous and synonymous substitution rates were estimated to be $1.16-3.30 \mathrm{X}$ $10^{-3}$ and $1.67-4.67 \times 10^{-3} /$ site/year, respectively, which was similar to other RNA viruses [17]. SARS-CoV has a probable recombinant history with lineages of $\beta-\mathrm{CoV} \& \beta-\mathrm{CoV}$ [18]. The studies on the sequence of the SARS-CoV TOR2 strain showed many smaller and specific recombinant regions have been acknowledged in the RNA-dependent RNA polymerase (nsp12 gene) at the following locations: nucleotides 13 392-13 610, 15 259-15 342, 15 974-16 108 and also in nsp9 and most of nsp10 gene located at 12 613-13 344, and parts of nsp14 (18 117-18 980) [18]. Another study analyzing the genome of the SARS-CoV CV7 strain had shown that seven putative recombination locations were found between SARS-CoV and six other CoVs: PEDV, TGEV, BCV, 229E, MHV and IBV. This further suggests that SARS-CoV emerged via serial horizontal transmission and by genetic recombination, enhancing the adaptation process to its human host [19] (Figure 1).

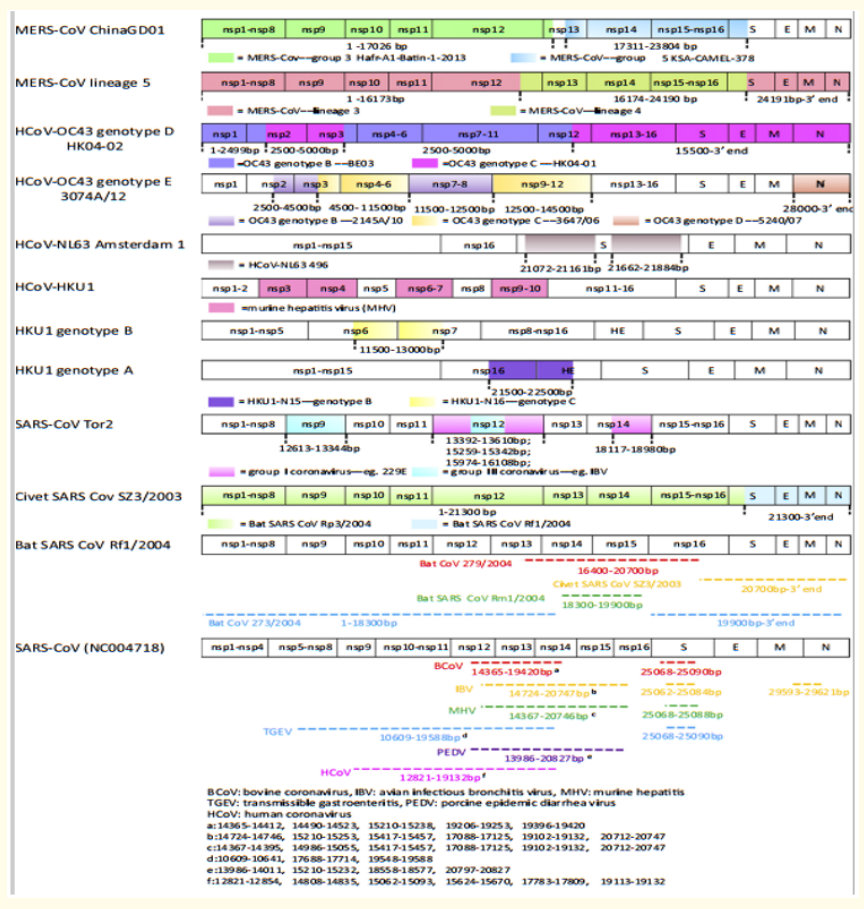

Figure 1: Genetic recombination indicated by colored regions at the genomic sites coronaviruses of zoonotic origin. Recombination shown by broken lines [1].
Transmission of 2019-nCoV into humans

nCoV-19 spread mainly from person-to-person through respiratory droplets when an infected person coughs or sneezes or close contacts with the infected person and the infected air droplets can reach into the oral cavity/nasal cavity of uninfected person and inhaled into the lungs. The envelope spike (S) protein mediates receptor binding and membrane fusion [20] and is crucial for determining host tropism and transmission capacity [21,22]. The spike protein of CoVs is functionally divided into the S1 domain responsible for receptor binding, and the S2 domain, responsible for cell membrane fusion and CoVs using angiotensin converting enzyme 2 receptor (ACE2) to enter in to the host cell [23]. 80\% of alveolar epithelial type II cells expressed ACE2 and act as a reservoir for viral invasion and providing viral replication site. ACE2R is also found in many extrapulmonary tissues like kidney, heart, endothelium, and luminal surface of intestinal epithelial cells which enforced to focused for fecal-oral transmission and containment of viral spread and multi-organ dysfunction in patients [24-27]. ACE2 regulate both the cross-species and human-to-human transmissions. The receptor-binding domain of $\mathrm{nCoV}-19$ fell within lineage $\mathrm{B}$ and was closer to that of SARS-CoV [28].

\section{Laboratory diagnosis of nCoV-19}

Quick collection and rapid examination of appropriate specimens from patients who are suspect of $\mathrm{nCoV}-19$ is a priority for clinical management and prevention of outbreak and should be directed by a laboratory experts. Suspect cases must be screened for nCoV-19 with nucleic acid amplification tests (NAAT), such as RT-PCR.

As co-infections can occur, all nCoV-19 suspect patients should be tested for $\mathrm{nCoV}-19$ virus regardless of whether another respiratory pathogen is found $[29,30]$.

\section{Specimen collection}

All specimens obtained for laboratory investigations should be handled as potentially infectious. Specimen examination for molecular testing would require biosafety level 2 or equivalent facilities, whereas viral culture requires biosafety level 3 facilities at minimum.

Specimens: Respiratory material should be collected: from upper respiratory tract: nasopharyngeal and oropharyngeal swab or wash in patients with mild or moderate disease, and in who has contact with a nCoV-19 case and/or from lower respiratory tract: sputum (if produced) and/or endotracheal aspirate, or bronchoalveolar lavage in severe cases. Additional clinical specimens may be collected since nCoV-19 virus has been isolated from blood and stool, as had the coronaviruses responsible for SARS and MERS 
[31,32]. Paired samples of serum are necessary for confirmation when serology test is validated and available with the first sample collected during the first week of illness and ideally the second sample collected 2 - 4 weeks later.

Shipment and Storage: Specimens for virus detection should reach the laboratory as soon as possible. Specimens that can be delivered promptly to the laboratory can be saved and shipped at 2 $-8^{\circ} \mathrm{C}$. When specimens are likely to be delayed reaching the laboratory, the use of viral transport medium is strongly recommended. Specimens may be frozen to $-20^{\circ} \mathrm{C}$ or ideally $-70^{\circ} \mathrm{C}$ and shipped on dry ice if further delays are expected. Repeated freezing and thawing of specimens should be avoided [31,32].

\section{Laboratory testing}

Nucleic acid amplification tests (NAAT)

Routine confirmation of cases of $\mathrm{nCoV}-19$ is based on examination of virus RNA to detect a unique sequences by NAAT, such as realtime reverse transcription polymerase chain reaction (rRT-PCR) with confirmation by nucleic acid sequencing when necessary. The viral genes targeted include the open reading frame $1 \mathrm{~A}, 1 \mathrm{~B}$ genes or nucleocapsid $(\mathrm{N})$ gene $[33,34]$.

Each NAAT run should include both external and internal controls, in addition to follow quality assurance procedures. When all controls have the expected performance and the result is positive, a specimen is considered positive and confirms the diagnosis of nCoV-19. One or more negative results don't rule out the possibility of nCOV-19 virus infection. Many factors could lead to a negative result in an infected individual, including:

- Poor quality of the specimen, containing little patient material (as a control, consider determining whether there is adequate human DNA in the sample by including a human target in the PCR testing).

- The specimen was collected at a late or very early stage of the infection.

- The specimen was not properly handled and shipped.

- Technical causes inherent in the test, such as virus mutation or PCR inhibition.

If a negative result is obtained from a patient with a high suspicion for nCoV-19 virus infection, particularly when only upper respiratory tract specimens were collected, additional specimens, including from the lower respiratory tract if possible, should be collected and tested [35].

\section{Serological testing}

Commercial and noncommercial serological tests are currently under development. Some studies with nCOV-19 serological data on clinical samples have been published [36,37].
Serological surveys can aid investigation of an ongoing outbreak and retrospective assessment of the attack rate or extent of an outbreak. In cases where NAAT assays are negative and there is a strong epidemiological link to $\mathrm{nCoV}-19$ infection, paired serum samples (in the acute and convalescent phase) could support diagnosis once validated serology tests are available.

\section{Viral culture}

nCoV-19 can be culture Human airway epithelial cell cultures and incubated at $37^{\circ} \mathrm{C}$ with $5 \% \mathrm{CO}_{2}$ and generated in an air-liquid interface for 4 to 6 weeks to form well-differentiated, polarized cultures resembling in vivo pseudostratified mucociliary epithelium [38]. The cells should be monitored daily with light microscopy, for cytopathic effects, and with RT-PCR, for the presence of viral nucleic acid in the supernatant. And can also demonstrated by electron microscopy [38].

For safety reasons, specimens from a suspect or documented nCoV-19 patient should not be submitted for viral culture as a routine diagnostic procedure.

Epidemiology of coronavirus SARS-CoV outbreak

In November 2002, unusual cases of "atypical pneumonia" of unknown cause occurred in Foshan City, Guangdong province, in China, where many health care workers became infected [39]. The infection was transferred to Hong Kong on 21 February, 2003, by a doctor who had looked after cases of atypical pneumonia in mainland China, which lead to subsequent outbreaks of severe pneumonia, and labeled by WHO as "severe acute respiratory syndrome" on 15 March, 2003 [40].

Many months have passed and many hundred cases of SARS were observed before SARS-CoV was identified the chains of human to human transmission which occurred in Toronto in Canada, Hong Kong, Singapore, Chinese Taipei, and Hanoi, Viet Nam. The studies has found that a strain of the coronavirus usually only found mutated in small mammals, allowing it to infect humans [41].

Following a strategy of isolating suspect people and screening all travelers by air from affected countries for signs of the infection, WHO declared the end of the SARS epidemic in July 2003. A total of 8276 SARS cases (which included 775 deaths) were reported from 37 countries and regions $[40,42]$.

This means the virus killed about 1 in 10 people who were infected. People over 65 years old were have high risk, about half of those who died from the SARS were belong to this age group. There were 4 occasions since July 2003, when SARS has reappeared, three of these were due to laboratory biosafety breaches in Singapore, Beijing, and Taipei, where seven cases were linked to one chain of transmission and with hospital spread. The fourth episode in 
Guangdong province, China, was due to four separated community acquired cases from December 2003 to January 2004. Three cases had been exposed to environmental or animals sources. There was no further community transmission [43].

\section{MERS-CoV outbreak}

The first report of MERS-CoV was in September 2012 when a novel bCoV was isolated from a male patient who had died in June 2012 of severe pneumonia and multiorgan failure in Saudi Arabia [44]. Later retrospective analyses recognized that the first cases of the outbreak involving thirteen individuals in Jordan, during March/April 2012 [45]. Since then MERS cases have been identified in many parts of the world: Arabian peninsula, Asia, Africa, Europe and North America (USA). MERS cases identified from outside the Middle East always have a history of recent travel from Arabian Peninsula or there were a close contact with a primary case.

based on recent study showed that the epidemic MERS-CoV occurs due to recombination of genetic material between the different lineages in dromedary camels in Saudi Arabia [46]. CoVs Lineages-3-and-5 were predominant during July and December 2014; however, lineage- 5 became dominant within the camel population by 2015 and also found associated in the outbreak of South Korea in 2015. A recent study showed a recombinant CoV between lineages 3 -and-4, or groups 3 and 5 of clade B in human infection at Riyadh city [46,47]. A total of 2502 laboratory-confirmed cases of MERS-CoV, were reported globally at the end of December 2019, which linked to 861 deaths (mortality rate: $34.4 \%$ ); most of these cases were identified in Saudi Arabia (2106 cases, including 783 deaths with a mortality rate of $37.2 \%$ ) [48].

The 50 - 59 year-old age group is the highest risk of getting a primary case infection. The 30 - 39 year-old age group has most risk to get secondary cases. The mortality is higher within the 50 - 59 year-old age group when they are primary cases, and among 70 - 79 year-olds age group when they are secondary cases [48].

Studies have confirmed a high seropositivity rate in camels in the Arabian Peninsula, and also showed seronegative results of infection for goats, cows or, sheep [49,50].

\section{nCoV-19 outbreak}

The regional office of World Health Organization (WHO) in Beijing had received in December 31, a notification of a number of patients have unknown cause pneumonia from Wuhan. By January 7, 2020, Chinese scientists had isolated a novel coronavirus (CoV) from patients in Wuhan [51].

As of March 25, 2020, 423692 cases of nCoV-19 have been confirmed, out of this 18922 (15\%) deaths and 109172 (85\%) have been recovered worldwide. 81218 (19.2\%) of them in China and 3281death in china, nCoV-19 is affecting 196 countries, area or territories around the world and the outbreak have been declared pandemic by WHO (Figure 2) [52].

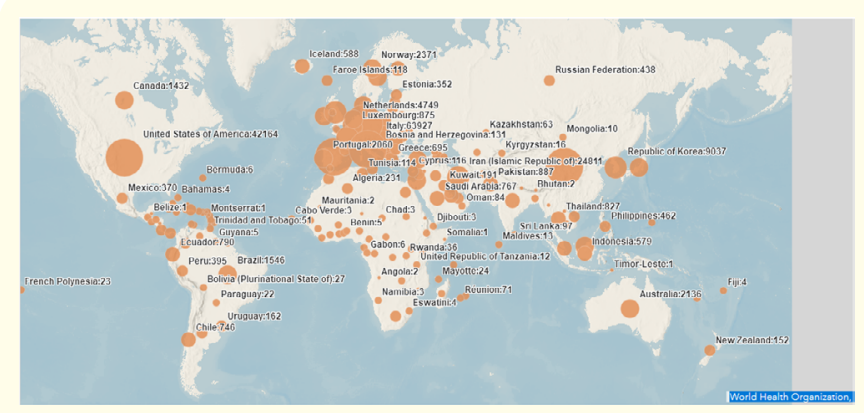

Figure 2: Countries, territories or areas with reported confirmed cases of nCOV-19, 25 March 2020..

Outside China, Italy nCoV-19 cases reached 69176 on 25 March, death toll reached 6820 and 8326 cases were recovered, making Italy the biggest coronavirus outbreak outside Asia after china. It is thought that the expanding air travel with China is the main cause of the high number of coronavirus infection cases in Italy. in USA 54916 positive cases and 784 deaths were found. Germany cases were 32991along with 159 deaths. In Spain 42058 cases with 2991 deaths.

A total of 13 countries in the Middle East currently have coronavirus, Iran has the highest number of coronavirus cases (24811 cases), followed by Qatar (526), Bahrain (292 cases), Kuwait (191 cases), Saudi Arabia (767 confirmed cases, 1 deaths), and in Turkey (1872 confirmed cases, 44 deaths) [52].

Iran has reported about 1934 deaths, which is among the highest cases outside China, after Italy and Spain and the first deaths in the Middle East. Other Middle East countries face the threat of coronavirus transmission from Iran.

Iraq is the neighbor of Iran has 316 confirmed cases on 25 March, the first nCoV-19 infection was determined on 24 February in an Iranian student in Najaf city. The most cases that confirmed in Iraq of a families who recently returned from Iran. So, Iraq has been closed the borders with Iran to protect their citizens form nCoV-19.

Increasing numbers of cases have also been reported in other countries across all continents except Antarctica, Republic of Korea (9137 confirmed cases, 126 deaths), Japan (1193 confirmed cases, 285 deaths), Thailand (934 confirmed cases, 4 death), India (562 confirmed cases, 10 deaths), Pakistan (1000 confirmed cases, 30 deaths), Canada (2792 confirmed cases, 26 deaths), Brazil (2247 confirmed cases, 46 deaths), according to WHO on March 25, 2020 [52]. 
According to that the crude mortality ratio (the number of reported deaths divided by the reported cases) is between $15-16 \%$ (Figure 2).

Initial data indicates that children are less affected than adults. The median age of patients is between 49 and 56 years [53,54]. Cases in children have been rare. Although most cases tend to be mild, whereas the older age and underlying conditions increase the risk for severe infection. Moreover, preliminary studies in China about household transmission suggest that adults are not infected from children. According to analytical study in Shenzhen China, most cases of nCOV-19 were mild (26\%) or moderate (65\%); and only (9\%) were severe [55].

It is suggested that the source of nCOV-19 is likely to be zoonotic according to the large number of nCOV19 confirmed cases who were exposed to the animal market in Wuhan City. The transmission from one Person to another led to the isolation of the cases who were subsequently administered a variety of treatments. Many procedures were done to reduce person to person transmission of nCOV-19 infection which lead to control the current outbreak [56].

\section{Treatment and preventions}

Currently there is no vaccination to prevent the patients by nCoV-19. Only prevention is the best way to avoid being exposed to this virus. Avoid close contact with the infected patients, avoid touching your eyes, nose and mouth, take healthy diet to have good health, use facemask to cover your mouth and nose area, clean your house frequently by using good disinfectant, maintain your Hand Hygiene by Washing your hands with soap and water for at least 20 seconds or alcohol-based hand sanitizer with at least $60 \%$ alcohol [57]. Favilavir (Favipiravir) has been approved as an investigational therapy for nCoV-19, reported by local media. The company met requirements to manufacture the generic version of Favipiravir but requires to further work on pharmacy and clinical pharmacology research said by The National Medical Products Administration. Chloroquine and Gilead's drug is said to be under trials in Beijing, Guangdong province, Shenzhen and at more than ten medical institutions in Wuhan, the epicentre of the nCoV-19 outbreak. A study conducted by US National Institutes of Health revealed that Remdesivir could prevent MERS-CoV and hopefully work on nCoV-19 and Wuhan Institute of Virology filed a request letter to work on Remdesivir in the beginning of March 2020 [58].

\section{Conclusion}

nCoV-19 came from animal and now transmitting from human to human through respiratory droplets, oro-faecal route and fomites in the immediate environment around the infected person. Currently the death rate of infected person from this virus is around
$20 \%$. There is no vaccination to prevent the patients by nCoV- 19 . Only prevention is the best way to avoid being exposed to this virus therefore WHO declared all countries to lockdown in this pandemic caused by nCoV-19. People should use medical mask, maintain physical distance, and maintain hand hygiene. A patho Detect kit manufactured by mylab's India are available to screen nCoV-19, can provide results in two and half hours. Favilavir, Chloroquine and Remdesivir drugs are under trials. nCoV-19 might be neutralized by providing high dose of soluble form of ACE2 and might recover cellular ACE2 activity by negative feed back system of renin angiotensin and protect the lung injury. Protein S1 domain of Spikesubunit based vaccine produced by Cell lines method, Inhibitor of transmembrane protease serine 2 to inhibit entry and viral spread can be try to curb this virus.

\section{Conflict of Interest Statement}

We declare that we have no conflict of interest.

\section{Ethical Approval}

Ethical approval for the study was taken from institutional research ethical committee.

\section{Funding}

No funding to declare.

\section{Bibliography}

1. Shuo Su., et al. "Epidemiology, Genetic Recombination, and Pathogenesis of Coronaviruses". Trends in Microbiology 24.6 (2016): 490-502.

2. Weiss SR and Leibowitz JL. "Coronavirus pathogenesis". Advances in Virus Research 81 (2011): 85-164.

3. Masters PS and Perlman S. "Coronaviridae". In: Knipe DM, Howley PM, eds. Fields virology. $6^{\text {th }}$ edition. Lippincott Williams and Wilkins (2013): 825-858.

4. Su S., et al. "Epidemiology, genetic recombination, and pathogenesis of coronaviruses". Trends in Microbiology 24 (2016): 490-502.

5. Cui J., et al. "Origin and evolution of pathogenic coronaviruses". Nature Reviews Microbiology 17 (2019): 181-192.

6. Zhong NS., et al. "Epidemiology and cause of severe acute respiratory syndrome (SARS) in Guangdong, People's Republic of China". Lancet 362 (2003): 1353-1358.

7. Ksiazek TG., et al. "A novel coronavirus associated with severe acute respiratory syndrome". The New England Journal of Medicine 348 (2003): 1953-1966. 
8. Drosten C., et al. "Identification of a novel coronavirus in patients with severe acute respiratory syndrome". The New England Journal of Medicine 348 (2003): 1967-1976.

9. Carter John., et al. "Virology: principles and applications”. John Wiley and Sons Ltd, The Atrium, Southern Gate, Chichester, West Sussex P019 8SQ, England (2007): 305-306.

10. Langereis MA., et al. "Attachment of mouse hepatitis virus to 0 acetylated sialic acid is mediated by hemagglutinin-esterase and not by the spike protein". Journal of Virology 84 (2010): 8970-8974.

11. Weiss SR and Navas-Martin S. “Coronavirus pathogenesis and the emerging pathogen severe acute respiratory syndrome coronavirus". Microbiology and Molecular Biology Reviews 69 (2005): 635-664.

12. Silva MT. "Neutrophils and macrophages work in concert as inducers and effectors of adaptive immunity against extracellular and intracellular microbial pathogens". Journal of Leukocyte Biology 87 (2010): 805-813.

13. Khan Salman., et al. "Evolution of ECG abnormalities in immune dysfunction exacerbation patients with chronic obstructive pulmonary disease". Acta Scientific Microbiology 3.4 (2020): 195-201.

14. Na Zhu., et al. "A Novel Coronavirus from Patients with Pneumonia in China, 2019". The New England Journal of Medicine 382 (2020): 727-733.

15. NJ Dimmock and AJ Easton. "Introduction to Modern Virology". Blackwell publishing Oxford OX4 2DQ UK $6^{\text {th }}$ edition (2007): 160-162.

16. Pyrc K., et al. "Mosaic structure of human coronavirus NL63, one thousand years of evolution". Journal of Molecular Biology 364 (2006): 964-973.

17. Zhao Z., et al. "Moderate mutation rate in the SARS coronavirus genome and its implications". BMC Evolutionary Biology 4 (2004): 21.

18. Stanhope MJ., et al. "Evidence from the evolutionary analysis of nucleotide sequences for a recombinant history of SARSCoV". Infection, Genetics and Evolution 4 (2004): 15-19.

19. Zhang XW., et al. "Testing the hypothesis of a recombinant origin of the SARS-associated coronavirus". Archives of Virology 150 (2005): 1-20.

20. Li F. "Structure, function, and evolution of coronavirus spike proteins". Annual Review of Virology 3 (2016): 237-261.
21. Lu G., et al. "Bat-to-human: spike features determining 'host jump' of coronaviruses SARS-CoV, MERS-CoV, and beyond". Trends in Microbiology 23 (2015): 468-478.

22. Wang Q., et al. "MERS-CoV spike protein: targets for vaccines and therapeutics". Antiviral Research 133 (2016): 165-177.

23. Zhao Y., et al. "Single-cell RNA expression profling of ACE2, the putative receptor of Wuhan COVID-19". (2020).

24. Crackower MA., et al. "Angiotensin-converting enzyme 2 is an essential regulator of heart function". Nature 417.6891 (2002): 822-828.

25. Danilczyk U., et al. "Essential role for collectrin in renal amino acid transport”. Nature 444.7122 (2006): 1088-1091.

26. Gu J., et al. "Multiple organ infection and the pathogenesis of SARS". Journal of Experimental Medicine 202.3 (2005): 415424.

27. Ding Y., et al. "Organ distribution of severe acute respiratory syndrome (SARS) associated coronavirus (SARS-CoV) in SARS patients: implications for pathogenesis and virus transmission pathways". The Journal of Pathology 203 (2004): 622-630.

28. He Y., et al. "Receptor-binding domain of SARS-CoV spike protein induces highly potent neutralizing antibodies: implication for developing subunit vaccine". Biochemical and Biophysical Research Communications 324 (2004): 773-781.

29. XU Kaijin., et al. "Management of Corona Virus Disease-19 (COVID-19) : the Zhejiang Experience". Journal of Zhejiang University (2020).

30. Yong Zhang., et al. "Isolation of 2019-nCoV from a Stool Specimen of a Laboratory-Confirmed Case of the Coronavirus Disease 2019 (COVID 19)" 2.8 (2020).

31. Shi X., et al. "Severe acute respiratory syndrome associated coronavirus is detected in intestinal tissues of fatal cases". The American Journal of Gastroenterology 100.1 (2005): 169-176.

32. Ding Y., et al. "Organ distribution of severe acute respiratory syndrome (SARS) associated coronavirus (SARS-CoV) in SARS patients: implications for pathogenesis and virus transmission pathways". The Journal of Pathology 203.2 (2004): 622-630.

33. Sameera Al Johani and Ali H Hajeer. "MERS-CoV Diagnosis: An Update". The Journal of Infection and Public Health 9.3 (2016): 216-219.

34. Leonie-Sophie Hecht and Angeles Jurado-Jimenez. "Verification and Diagnostic Evaluation of the RealStar ${ }^{\circ}$ Middle East Respiratory Syndrome Coronavirus (N Gene) Reverse transcription-PCR Kit 1.0". Future Microbiology 14 (2019): 941-948. 
35. WHO. Coronavirus disease (COVID-19) technical guidance: Surveillance and case definitions (2020).

36. Bai Shaoli., et al. "Analysis of the first family epidemic situation of new coronavirus pneumonia in Gansu Province". Chinese Journal of Preventive Medicine (2020): 54.

37. Shu-Yuan Xiao., et al. "Evolving status of the 2019 novel coronavirus infections: proposal of conventional serologic assays for disease diagnostics and infection monitoring". Journal of Medical Virology (2020): 1-4.

38. Jonsdottir HR and Dijkman R. "Coronaviruses and the human airway: a universal system for virus-host interaction studies". Virology Journal 13 (2016): 24.

39. Zhao Z., et al. "Description and clinical treatment of an early outbreak of severe acute respiratory syndrome (SARS) in Guangzhou, PR China". Journal of Medical Microbiology 52 (2003): 715-720.

40. WHO. "Summary of probable SARS cases with onset of illness" (2016).

41. Shi $\mathrm{Z}$ and $\mathrm{Hu} \mathrm{Z}$. "A review of studies on animal reservoirs of the SARS coronavirus". Virus Research 133 (2008): 74-87.

42. Peiris JS., et al. "SARS study group. Coronavirus as a possible cause of severe acute respiratory syndrome". Lancet 361.9366 (2003): 1319-1325.

43. David S C Hui and Alimuddin Zumla. "Severe Acute Respiratory Syndrome: Historical, Epidemiologic, and Clinical Features". Infectious Disease Clinics of North America 33 (2019): 869-889.

44. Zaki AM., et al. "Isolation of a novel coronavirus from a man with pneumonia in Saudi Arabia". The New England Journal of Medicine 367 (2012): 1814-1820.

45. Al-Abdallat MM., et al. "Hospital-associated outbreak of middle East respiratory syndrome coronavirus: a serologic, epidemiologic, and clinical description". Clinical Infectious Diseases 59.9 (2014): 1225-1233.

46. Sabir JS., et al. "Co-circulation of three camel coronavirus species and recombination of MERS-CoVs in Saudi Arabia". Science 351 (2016): 81-84.

47. Wang Y., et al. "Origin and possible genetic recombination of the Middle East respiratory syndrome coronavirus from the first imported case in China: phylogenetics and coalescence analysis". Mbio 6 (2015): e01280-01215.
48. WHO. MERS situation (2019).

49. Reusken CB., et al. "Middle East respiratory syndrome coronavirus neutralising serum antibodies in dromedary camels: a comparative serological study". The Lancet Infectious Diseases 13.10 (2013) : 859-866.

50. Reusken CB., et al. "Middle East Respiratory Syndrome coronavirus (MERS-CoV) serology in major livestock species in an affected region in Jordan, June to September 2013". European Surveillance 18.50 (2013): 20662.

51. Carlos Del Rio and Preeti N Malani. "Novel Coronavirus-Important Information for Clinicians". Journal of the American Medical Association (2020).

52. “Coronavirus disease 2019 (COVID-19) Situation Report 48" (2020).

53. Chen N., et al. "Epidemiological and clinical characteristics of 99 cases of 2019 novel coronavirus pneumonia in Wuhan, China: a descriptive study". Lancet 395.10223 (2020): 507-513.

54. Huang C., et al. "Clinical feature of patients infected with 2019 novel coronavirus in Wuhan, China". Lancet 395.10223 (2020): 497-506.

55. Qifang Bi and Yongsheng Wu. "Epidemiology and Transmission of COVID-19 in Shenzhen China: Analysis of 391 cases and 1,286 of their close contacts". Med Rxiv (2020).

56. Hussin A Rothan and Siddappa N Byrareddy. "The Epidemiology and Pathogenesis of Coronavirus Disease (COVID-19) Outbreak". Journal of Autoimmunity (2020).

57. https://www.cdc.gov/coronavirus/2019-ncov/about/prevention-treatment.html

58. https://www.pharmaceutical-technology.com/news/chinafavilavir-testing-approval/

\section{Assets from publication with us}

- Prompt Acknowledgement after receiving the article

- Thorough Double blinded peer review

- Rapid Publication

- Issue of Publication Certificate

- High visibility of your Published work

Website: www.actascientific.com/

Submit Article: www.actascientific.com/submission.php

Email us: editor@actascientific.com

Contact us: +919182824667 